\title{
Arthroscopic Resection of a Chondroma of the Hoffa Fat Pad: Case Report and Review of Literature
}

\author{
Otmane Hiba1 ${ }^{*}$, Rachid Ait Mouha1, Amine Belmoubarik¹, Eric Bacheville², \\ Jean Hani Tawil ${ }^{2}$ \\ ${ }^{1}$ Department of Orthopaedic Surgery, Ibn Rochd Hospital, Casablanca, Morocco \\ ${ }^{2}$ Department of Orthopaedic Surgery, Orsay Hospital, Orsay, France \\ Email: dr-othmane@hotmail.fr, aitmouharachid@gmail.com, aminovich2005@gmail.com, \\ e.bacheville@ch-orsay.fr, h.j.tawil@ch-orsay.fr
}

Received 20 September 2015; accepted 7 October 2015; published 13 October 2015

Copyright (C) 2015 by authors and OALib.

This work is licensed under the Creative Commons Attribution International License (CC BY). http://creativecommons.org/licenses/by/4.0/

(c) (i) Open Access

\section{Abstract}

The Hoffa's disease is a rare and little-known cause of anterior knee pain. It was first reported by Albert Hoffa in 1904. It is due to chronic impingement of fat pad Hoffa between the femur and the tibia during knee extension. The formation of the Hoffa's chondroma appears to be the final phase of acute-chronic transformation process of this disease. We present a case of chondroma of Hoffa which received complete resection under arthroscopy. We show in this work the clinical appearance, radiological and pathological chondroma of the Hoffa.

\section{Keywords}

\section{Chondroma, Hoffa's Disease, Resection, Arthroscopic}

Subject Areas: Orthopedics, Surgery \& Surgical Specialties

\section{Introduction}

Hoffa's disease is an intrinsic pathology of infra-patellar fat pad. It was described for the first time by Albert Hoffa in 1904 and defined as an acute or chronic inflammation of the infra-patellar fat. It involves anterior pain below the patella as main symptom with often a sensation of knee instability. Recurrent episodes of hydrarthrosis are reported especially in chronic cases.

The test of Hoffa is considered positive when the patient complains a pain or apprehension when the examiner presses by his two thumbs on the knee along both edges of the patellar tendon during passage from flexion to ${ }^{*}$ Corresponding author.

How to cite this paper: Hiba, O., Mouha, R.A., Belmoubarik, A., Bacheville, E. and Tawil, J.H. (2015) Arthroscopic Resection of a Chondroma of the Hoffa Fat Pad: Case Report and Review of Literature. Open Access Library Journal, 2: e1993. 
extension.

Chondroma of Hoffa seems to be the end-stage of this disease. It's considered as rare mild cartilaginous tumors. The etiology of this lesion is not well known, but it results probably from repeated traumas responsible for metaplasia of extra-synovial mesenchymatous cells.

\section{Case Report}

A 40-year-old man complained of pain in his right knee earlier with a feeling of knee instability evolving for 1 year following an occupational accident with a twisting mechanism without changing the range of motion and absence of visible or palpable mass. He received an MRI that objectified a well individualized chondroma of Hoffa without meniscal or ligament lesion associated (Figure 1).

The first arthroscopic exploration revealed several fragments squamous pearly white of cartilaginous aspect filling the joint cavity and removing probably from the chondroma (Figure 2).

After washing aspiration we performed complete resection of chondroma under arthroscopic control after extension of arthroscopic portal. The tissue removed was white-tan, shiny, cartilaginous material. The mass measured $4 \times 2 \times 2 \mathrm{~cm}$ (Figure 3 and Figure 4 ).

The resection was easy and the chondroma was well bounded. The aspect of the nearby tissue was normal.

The postoperative course was simple and the patient was able to return to work after two weeks. The pathologic anatomical examination of the surgical specimen found in a chondroma.

After a follow-up during six months, the pain decreased significantly and the sensation of instability disappeared.

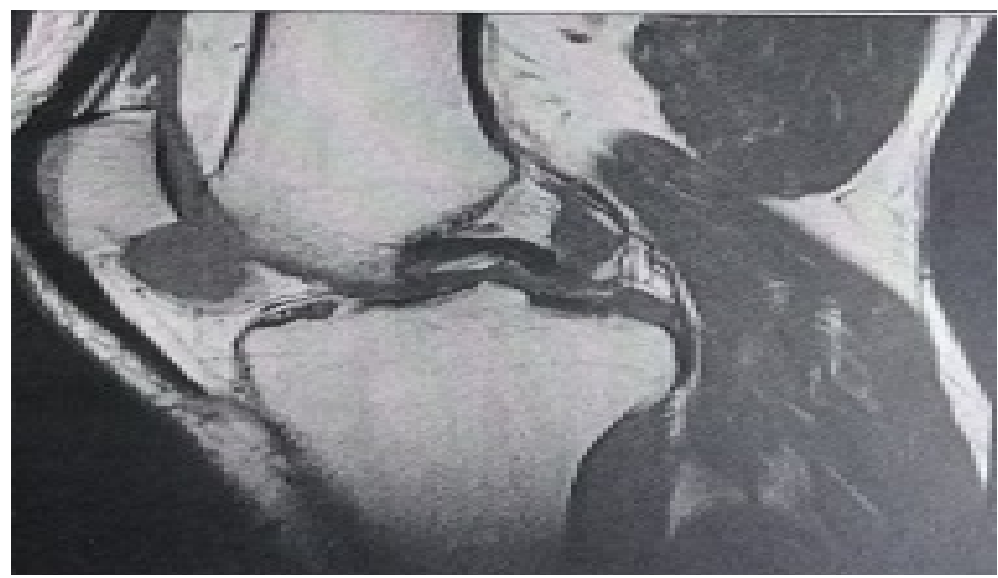

Figure 1. MRI image: in patellar tracking intra "Hoffa".
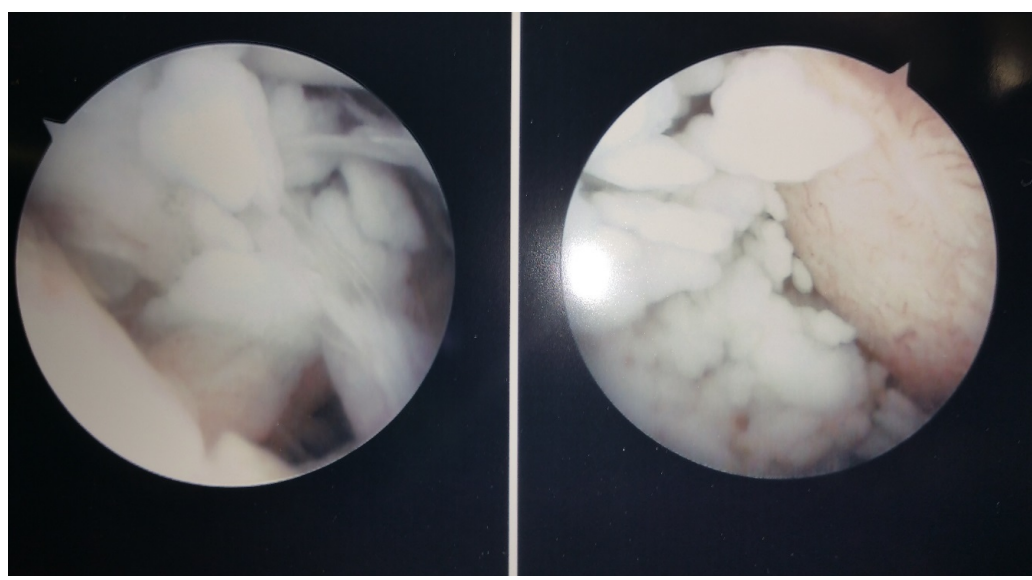

Figure 2. Intraoperative arthroscopic aspect of fragments removing from the chondroma. 


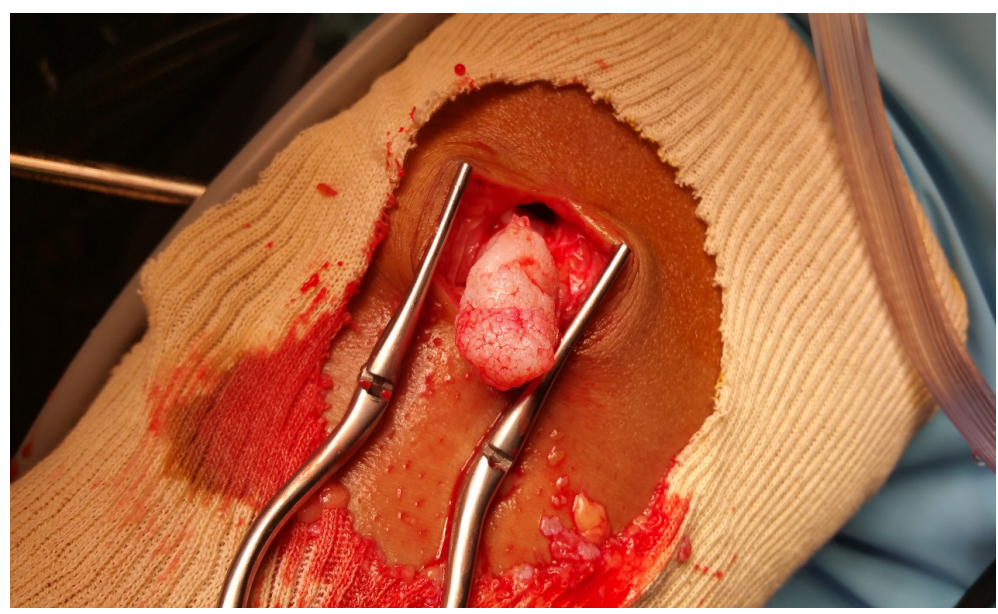

Figure 3. Arthroscopic removal of chondroma.

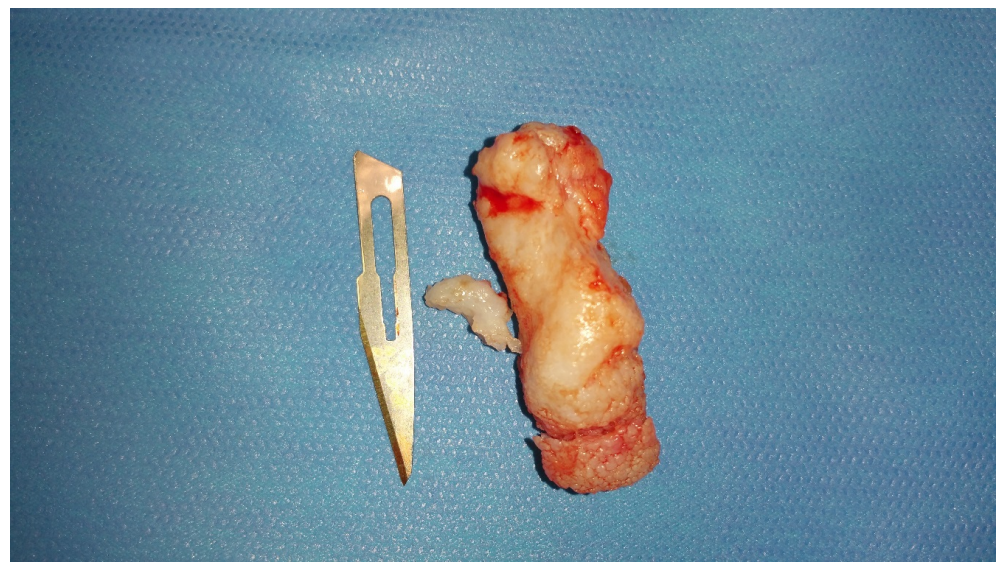

Figure 4. Macroscopic appearance of chondroma.

\section{Discussion}

Hoffa's disease is determined by hyperplasia of the fatty tissue which can sometimes reach the joint and cause expansion of the capsule [1]. Age of onset is between 12 and 75 years old with a mean of 49.4 years old [2]. Although the etiology of this hyperplasia remains obscure, it is almost always associated with a history of knee injuries in young patients leading to the impingement and inflammation of infra-patellar fat [3]-[5]. The chondroma of Hoffa seems to be the final stage of processing adipocytes into chondrocytes and osteoblasts [6].

Hoffa's fat pad is intracapsular but extra-synovial. It's limited by the patella up, the tibia and the infra-patellar purse down, the patellar ligament and the capsule forward and synovial joint back [7] [8]. The clinical picture is most associated earlier pain type of infra-patellar discomfort without modification of articular amplitudes associated to a sensation of instability of the knee especially in up and down stairs. At an advanced stage, a palpable mass more or less visible on clinical examination can be objectified [9]-[11]. The infiltration of corticosteroids in early stage of disease may be offered as a preoperative proposition [12].

MRI is the gold standard for analyzing fat Hoffa. The most suggestive MRI sign is presence of an important infra-patellar edema of fat body and synovial recess associated with a fibrous area that may contain calcifications. In case of intracapsular chondroma, this examination reveals an heterogeneous mass with a T1 hyposignal and T2 heterogeneous signal. Adjacent bone erosion is possible. Radiography has an interest especially during ossified stages [13] [14].

\section{Conclusion}

Conservative treatment is proposed first at all and consists of a strengthening of the quadriceps associated with 
an anti-inflammatory therapy. Infiltration of corticosteroids in Hoffa fat can also be suggested. Arthroscopic resection remains the treatment of choice in case of failure of conservative treatment.

\section{Declaration of Interest}

The authors declare that there are no conflicts of interest.

\section{References}

[1] Hoffa, A. (1904) The Influence of the Adipose Tissue with Regard to the Pathology of the Knee Joint. JAMA, 43, 795-796.

[2] Jang, S.K., Hong, H.J., Han, E.M., Kang, S.M., Yoo, J.Y. and Ahn, I.O. (2008) Intracapsular and Paraarticular Chondroma of the Infrapatellar Hoffa's Fat Pad: A Case Report. JKSMRM, 12, 197-200.

[3] Ruyera, A., Cytevala, C., Hamoui, M., Dallaudiere, B., Zarqane, H., Viala, P. and Larbi, A. (2014) La maladie de Hoffa: à propos de 5cas. Journal de Radiologie Diagnostique et Interventionnelle, 95, 1068-1073. http://dx.doi.org/10.1016/j.jradio.2013.03.010

[4] Krebs, V.E. and Parker, R.D. (1994) Arthroscopic Resection of an Extrasynovial Ossifying Chondroma of the Infrapatellar Fat Pad: End-Stage Hoffa's Disease? Arthroscopy: The Journal of Arthroscopic \& Related Surgery, 10, 301304. http://dx.doi.org/10.1016/S0749-8063(05)80117-3

[5] Park, J.-H., Park, J.-H., Lee, A.-H. and Lee, D.-H. (2011) An Unusual Presentation of Hoffa’s Disease in an Elderly Patient with No Trauma History: A Case Report. Acta Orthopaedica et Traumatologica Turcica, 45, 195-199. http://dx.doi.org/10.3944/AOTT.2011.2510

[6] Turhan, E., Doral, M.N., Atay, A.Ö. and Demirel, M. (2008) A Giant Extrasynovial Osteochondroma in the Infrapatellar Fat Pad: End Stage Hoffa’s Disease. Archives of Orthopaedic and Trauma Surgery, 128, 515-519. http://dx.doi.org/10.1007/s00402-007-0397-5

[7] Henon, A., Jomaah, N., Pradel, C., Ennouchi, S., Arrivé, L. and Tubiana, J.M. (2005) Imagerie de la graisse de Hoffa: aspect normal et aspect pathologique. Journal de Radiologie, 86, 1529.

[8] Singh, V.K., Shah, G., Singh, P.K. and Saran, D. (2009) Extraskeletal Ossifying Chondroma in Hoffa's Fat Pad: An Unusual Cause of Anterior Knee Pain. Singapore Medical Journal, 50, e189-e192.

[9] Bettoumi, M., Zéhi, K., Rbai, H., Tlili, N. and Zouari, M. (2009) Osteochondroma of the Infrapatellar Fat Pad. A Report of Two Cases. Tunisie Orthopédique, 2, 93-95.

[10] Benchakroun, M., Bennis, A., Zaddoug, O., Boukhris, J., Boussouga, M. and Jaafar, A. (2014) Hoffa's Disease. Revue Marocaine de Rhumatologie, 29, 38-43.

[11] Rodriguez-Peralto, J.L., Lopez-Bareat, F. and Gonzalez-Lopezt, V. (1997) Intracapsular Chondroma of the Knee: An Unusual Neoplasm. International Journal of Surgical Pathology, 5, 49-53. http://dx.doi.org/10.1177/106689699700500108

[12] Duri, Z.A., Aichroth, P.M. and Dowd, G. (1996) The Fat Pad. Clinical Observations. The American Journal of Knee Surgery, 9, 55-66.

[13] Jacobson, J.A., Lenchik, L., Ruhoy, M.K., Schweitzer, M.E. and Resnick, D. (1997) MR Imaging of the Infrapatellar Fat Pad of Hoffa. Scientific Exhibit, 17, 675-691.

[14] Gallagher, J., Tierney, P., Murray, P. and O’Brien, M. (2005) The Infrapatellar Fat Pad: Anatomy and Clinical Correlations. Knee Surgery, Sports Traumatology, Arthroscopy, 13, 268-272. http://dx.doi.org/10.1007/s00167-004-0592-7 